\title{
Clinical and Molecular Cytogenetic Study of 38 Williams-Beuren Syndrome Tunisian Patients
}

\author{
Ines Ouertani ${ }^{*}$, Myriam Chaabouni ${ }^{1}$, Imen Chelly ${ }^{2}$, Lilia Kraoua1, Faouzi Maazoul1, \\ Mediha Trabelsi' ${ }^{1}$, Rym Meddeb ${ }^{1}$, Rafik Boussaada ${ }^{3}$, Hatem Azzouz ${ }^{4}$, Fatma Charfi ${ }^{5}$, \\ Emira Ben Hamida6, Ahmed Meherzi'7, Ridha Mrad'1, Habiba Bouhamed-Chaabouni1 \\ ${ }^{1}$ Service des Maladies Congénitales et Héréditaires, Hôpital Charles Nicolle, Tunis, Tunisie \\ ${ }^{2}$ Service de Pédiatrie, Hôpital Régional de Bizerte, Bizerte, Tunisie \\ ${ }^{3}$ Service de Cardiologie Pédiatrique, Hôpital la Rabta, Tunis, Tunisie \\ ${ }^{4}$ Service de Pédiatrie, Hôpital la Rabta, Tunis, Tunisie \\ ${ }^{5}$ Service de Pédopsychiatrie, Hôpital Razi, La Mannouba, Tunisie \\ ${ }^{6}$ Service de Néonatologie, Hôpital Charles Nicolle, Tunis, Tunisie \\ ${ }^{7}$ Service de Pédiatrie, Hôpital Mongi Slim, La Marsa, Tunisie \\ Email: "nannoussa56@yahoo.fr
}

Received 2 July 2014; revised 3 August 2014; accepted 4 September 2014

Copyright (C) 2014 by authors and Scientific Research Publishing Inc.

This work is licensed under the Creative Commons Attribution International License (CC BY).

http://creativecommons.org/licenses/by/4.0/

c) (i) Open Access

\section{Abstract}

Background: Williams-Beuren syndrome (WBS) is a rare multi-system genomic disorder, caused by 7 q11.23 microdeletion with a prevalence of $1 / 7500-1 / 20,000$ live births. Clinical phenotype includes typical facial dysmorphism (elfin face), mental retardation associated with a peculiar neuropsychological profile and congenital heart defects. Other signs are occasional like ocular, skeletal, renal and dental anomalies. Here in, we present 38 WBS Tunisian patients. Methods: All patients underwent a genetic consultation and in order to confirm the clinical diagnosis of WBS, fluorescent in situ hybridization (FISH) was applied on metaphase spreads using the dual color locus specific identifier WBS region probe (Vysis probe) that hybridized to the ELN and LIMK1 loci at 7q11.23 and to control loci D7S486 and D7S522 at 7q31. About 15 to 20 metaphases were analyzed for each case. Results: The mean age at diagnosis was 4 years and 4 months. All patients showed facial dysmorphism. $66 \%(23 / 35)$ have cardiovascular anomaly, peripheral pulmonary stenosis $(10 / 35)$ is interestingly more frequent than the supravalvular aortic stenosis $(7 / 35)$. Various degrees of mental retardation were present and a normal intelligence was found in three patients. The unique cognitive profile was found in all patients except one who had autistic disorders. Ocular anomalies $(13 / 38)$ were less frequent than described, the skeletal anomalies too

\footnotetext{
${ }^{*}$ Corresponding author.
} 
$(12 / 38)$. Dental malformations were frequent $(22 / 32)$. Idiopathic hypercalcemia was present in $50 \%$ of children less than one year (2/4). Conclusions: WBS was a rare disorder, cardinal signs (facial dysmorphism, mental retardation and cardiovascular defects) were found in our patients in the same proportions than described. The occasional clinical signs have proportion different of precedent reported like hypercalcemia, ocular and dental anomalies. The identification of the different clinical signs in WBS patients permits to establish a strategy of follow up.

\section{Keywords}

Williams-Beuren Syndrome, FISH, Dysmorphism, Cardiovascular Malformation

\section{Background}

Williams-Beuren syndrome (WBS, OMIM \#194050) is a multisystem disorder caused by hemizygous deletion of 1.5 to $1.8 \mathrm{Mb}$ on chromosome 7q11.23, which contains approximately 28 genes [1]. About these genes, only the elastin gene $(E L N)$ has been definitely associated with a specific feature of the phenotype, namely supravalvar aortic stenosis and systemic arterial anomalies [2]-[4].

WBS was first identified as a distinct clinical entity in 1961-1962 independently by two authors [5] [6]. It is estimated to occur in approximately 1 in 7500 life-births [7]. Males and females are equally affected.

Clinical phenotype is heterogeneous in severity and manifestations. The main clinical features are facial dysmorphism (elfin face), mild to moderate mental retardation associated with a characteristic neuropsychological profile, congenital heart defects (most commonly supravalvar aortic stenosis (73\%)) and growth retardation during the first two years of life. Idiopathic infantile hypercalcemia is less frequent than initially thought and it generally resolves spontaneously [8] [9].

Facial features include broad forehead with bitemporal narrowing, low nasal root, bulbous nasal tip, periorbital fullness, stellate iris pattern, malar flattening, full cheeks, long philtrum, full lips, wide mouth, and dental malocclusion with small and widely spaced teeth. Almost every child with WBS shows the typical dysmorphic facies and although these features are often subtle, they tend to become more distinctive with advancing age [10].

Older children and adults have a more gaunt appearance of the face with a prominent supraorbital ridge and long neck [10]-[12].

The majority of children with WBS have cardiovascular anomalies [6] [8]. The cardiovascular defect is often progressive requiring surgical repair especially the supravalvar aortic stenosis [4] [10] [11] [13]. Because the elastin protein is an important component of elastic fibers in the arterial wall, any artery may become narrowed. Peripheral pulmonary artery stenosis (41\%), coarctation of the aorta, renal artery stenosis, and systemic hypertension are complications that may be present [4] [9] [13].

Patients with WBS are generally thought to display a typical cognitive and behavioral profile [14]-[16] characterized by a mild to moderate intellectual disability (mean IQ 56) [16] associated with hyperacusis, severe impairments in visuo-spatial abilities and numeric processing, contrasting with relative good short term verbal memory [17], relative preservation of face processing, great receptivity to music [18], and linguistic and socialaffective skills. The latter abilities often produce a "cocktail party" personality including overfriendliness, lack of fear with strangers, strong pro-social compulsion [19], excessive talkativeness, and verbal fluency with extensive and expressive speech rich in vocabulary at least in adulthood.

Here we report on the results of a clinical analysis on a cohort of 38 WBS patients.

\section{Materials and Methods}

We examined 38 patients referred to the Department of Congenital and Hereditary Diseases of the Charles Nicolle Hospital, Tunis, Tunisia, for genetic investigation.

This study was approved by the ethics committee on Charles Nicolle hospital of Tunis, Tunisia. Informed consent to participate in the study was obtained from parents.

Main reasons of investigation demand were the presence of: heart murmur or congenital heart disease: 2 pa- 
tients (5\%); developmental delay and/or intellectual deficiency: 12 patients (32\%); dysmorphic features: 15 patients (39\%); clinical suspicion of WBS: 8 patients (21\%) and short stature: one patient (3\%).

The mean age of referred patients was 4 years and 4 months with extreme ages of 30 days and 13 years.

All patients underwent a genetic consultation: personal history was documented including prenatal signs, psychomotor development and growth progression. Physical examination was performed for morphology description and clinical evaluation.

Cardiac investigation: blood pressure measurement, echocardiography and Doppler echocardiography.

Nephrologic investigation: urinalysis, renal and urinary tract ultrasound examination, creatinine serum level dosage. Ophthalmologic, endocrinologic (TSH, fT3, fT4, thyroid ultrasound examination), X-Ray and biochemical assessments were performed if possible. Chromosomes analysis was performed on blood sample using conventional R-banding techniques for all patients.

In order to confirm the clinical diagnosis of WBS, fluorescent in situ hybridization (FISH) was applied on metaphase spreads using the dual color locus specific identifier WBS region probe (Vysis probe) that hybridizes to the ELN and LIMK1 loci at 7q11.23 and to control loci D7S486 and D7S522 at 7q31. About 15 to 20 metaphases were analyzed for each case.

FISH was applied on metaphase spread of parents when availabe in order to detect deletion or rearrangement.

\section{Results}

All patients except one had a normal karyotype.

FISH analysis revealed the 7q11.23 microdeletion in 37 subjects (Figure 1).

No mosaicism was detected.

The patient with an abnormal karyotype had an apparently balanced translocation between chromosomes 5 and 7: 46,XY,t(5;7)(q35;q11.22)dn, parents' karyotypes were normal.

For this patient, no 7q11.23 microdeletion was detected using the WBS region probe (Vysis probe); the breaking point was proximal to the ELN locus. Other FISH probes were used for a better characterization of the chromosomal aberration (data not shown).

All parents of our patients were examinated and they did not show clinical features of WBS.

FISH analysis performed for 25/76 of these parents did not reveal 7q11.23 microdeletion or microrearrangement supporting the theory of sporadic occurrence of WBS.

The sex ratio was 2.16: 26 patients were male and 12 were female.

15/38 patients showed post-natal growth deficiency, information of pre-natal growth deficiency was not available for all the patients.

All patients showed the typical facial dysmorphic features (Figure 2).

Among our 38 patients, 6 were aged 6 months or less and were excluded from the evaluation of developmental delay and/or intellectual deficiency.

Delayed development and intellectual deficiency were seen in 29/32, the degree of intellectual deficiency that each patient displayed, however, was not documented.

From the three patients who were evaluated as having normal intellectual skills, two patients had average intelligence and were integrated in an ordinary school, and the third one had low average intelligence.

About the 29 children having intellectual deficiency, according to their socio-economical conditions and the parents' implication in their education, they irregularly attended specialized institutions for children with intellectual deficiency.

One patient affected by mild mental retardation showed impaired social interaction, restricted activities, stereotyped mannerism and regression of language corresponding to autistic features.

Except the patient showing the autistic features, the unique cognitive profile of WBS with overfriendliness and an empathetic nature was found in all patients aged more than 5 years. Anxiety which is a common finding in the patients with WBS was diagnosed in two patients aged 3 and 4 years.

Hyperacusis was not systematically investigated; only 6 patients were presenting this feature.

All the subjects except three had echocardiography (35/38). The three patients who had not echocardiography had already heart murmur.

Congenital cardiopathy was found in 23/35 patients. Supravalvular aortic stenosis was detected by echocardiography in 7/35 patients. Peripheral pulmonary stenosis was found in 10/35 patients, 3 patients showed an association of supravalvular aortic stenosis and peripheral pulmonary stenosis. 2/35 had ventricular septal defect, 


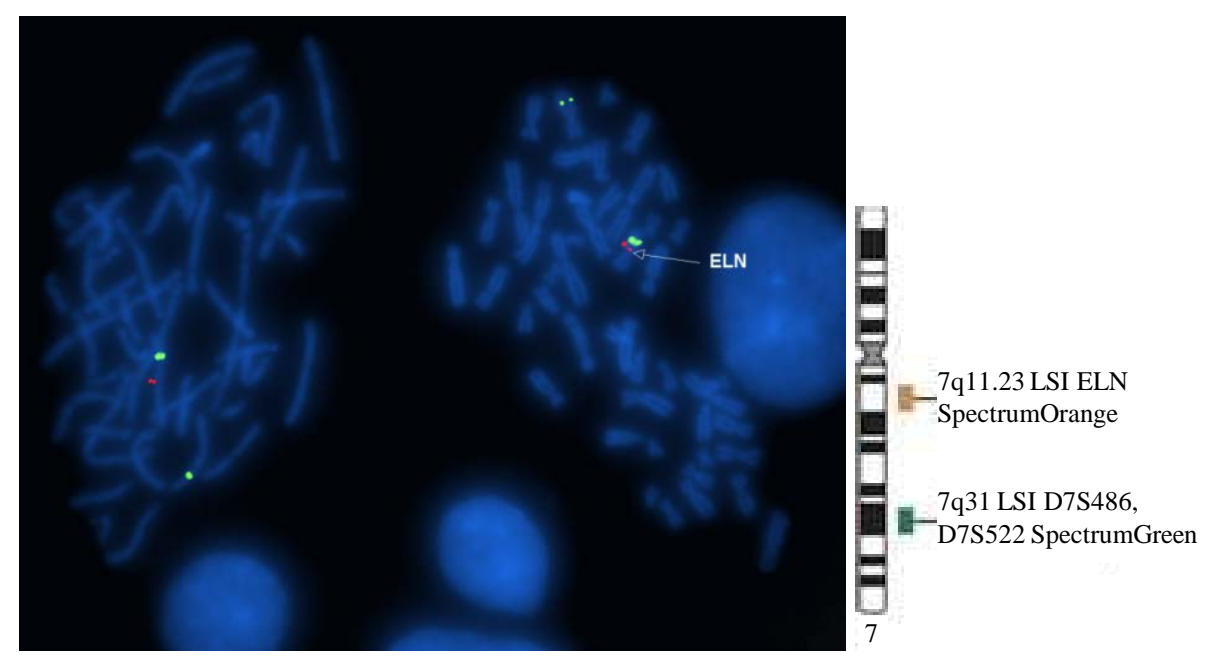

Figure 1. FISH shows an orange signal specific for Williams-Beuren syndrome chromosome region at loci 7q11.23 and a green signal specific for control loci at 7q31.

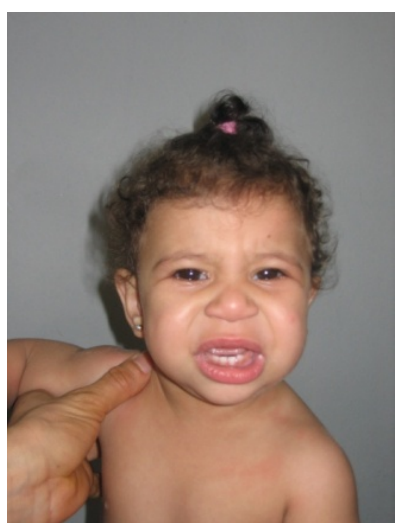

(a)

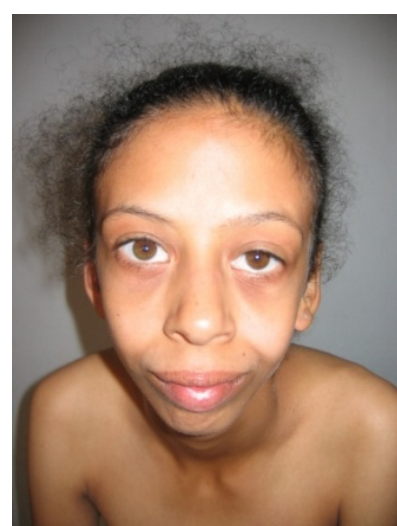

(b)

Figure 2. Two girls from our series, (a) aged 18 months, (b) aged 18 years. Note the typical facial dysmorphism: broad forehead with bitemporal narrowing, low nasal root, bulbous nasal tip, periorbital fullness, malar flattening, full cheeks, long philtrum, full lips and wide mouth.

and 1/35 patient had complex cardiac reorganization. No surgical correction was required for any patient at the time when they were attending our clinics.

All the other malformations previously reported were seen in our patients: ocular anomalies (13/38), dental anomalies in patients aged more than 6 months (22/32), skeletal anomalies (12/38), urinary tract anomalies (3/38) and hernias (9/38).

Clinical findings are summarized in Table 1.

Hypercalcemia is reported as a feature detected essentially in first year of life.

In our series, 9 patients were aged 12 months or less; 4 of them were available for idiopathic infantile hypercalcemia testing. Elevated blood calcium level was detected twice. None of the two patients showed clinical manifestations of hypercalcemia or required medical treatment.

Hypothyroidism was detected in 5 patients from 19 tested, no clinical manifestations were present and no medical treatment was prescribed, regular periodic review was indicated.

\section{Discussion}

WBS is a multisystem disorder caused by hemizygous deletion of 1.5 to $1.8 \mathrm{Mb}$ on chromosome $7 \mathrm{q} 11.23$, it is 
Table 1. Clinical findings in our patients (with American Academy of Pediatrics [AAP] data [9] for comparison).

\begin{tabular}{lccc}
\hline \multicolumn{1}{c}{ Anomalies } & Patients & (\%) & AAP data (\%) \\
\hline Cardiovascular malformations & & & 75 \\
Supravalvular aortic stenosis & $7 / 35$ & $(20)$ & 50 \\
Peripheral pulmonary stenosis & $10 / 35$ & $(28.6)$ & 10 \\
Ventricular septal defect & $2 / 35$ & $(5.7)$ & - \\
Complex cardiac reorganization & $1 / 35$ & $(2.8)$ & 50 \\
Ocular anomalies & $13 / 38$ & $(34.3)$ & 95 \\
Dental anomalies & $22 / 32$ & $(69)$ & 90 \\
Skeletal anomalies & $12 / 38$ & $(31.4)$ & 20 \\
Urinary tract anomalies & $3 / 38$ & $(8.6)$ & 50 \\
hernias & $9 / 38$ & $(25.7)$ & 15 \\
Hypercalcemia & $2 / 4$ & $(50)$ & 2 \\
Biochemical hypothyroidism & $6 / 19$ & $(31.6)$ & \\
\hline
\end{tabular}

also called contiguous-gene-deletion disorder.

Recognition of WBS usually starts with clinicians, however, clinical diagnostic criteria [9] [20] are modestly useful compared with FISH testing. FISH involving ELN-specific probes establishes the diagnosis of WBS by revealing the presence of a single $E L N$ allele only rather than two alleles.

We report here 38 cases of clinical WBS, 37 patients having a normal karyotype with microdeletion on chromosome 7q11.23 confirmed by FISH, the last patient with WBS features had no microdeletion and an abnormal karyotype: 46,XY,t(5;7)(q35;q11)dn.

WBS' patients with balanced translocation were previously reported with chromosomal break point in the 7q11.23 region and precisely in the ELN locus [21] [22].

Dysmorphic features are the only constant clinical finding and the first phenotypic element evocating the WBS.

Cardiovascular anomalies were detected in 24/35 (68\%), which is less frequent than previously reported [9] [12]. Peripheral pulmonary stenosis was the most common cardiovascular anomaly (10/35) in our patients, followed by supravalvular aortic stenosis (7/35) which is interestingly different from literature where supravalvular aortic stenosis is the most common cardiovascular anomaly [9].

Delayed development and/or intellectual deficiency was present in 29/32 (90\%) of our series, these findings are in agreement with previous literature data [9] [23] [24].

Two patients showed no intellectual deficiency confirming that normal intelligence is compatible with WBS [9].

One case showed the association with autistic features. Commonly, WBS patients showed overfriendliness and an empathetic nature which is totally contrasting with autism, nevertheless, WBS patients showing autistic features were already reported [25].

In fact, some patients have smaller and/or larger deletions of the region, and their clinical features vary from isolated arteriopathy to classic WBS phenotype without mental retardation on with autism spectrum behavior [26] [27].

According to literature reports [4] [28] [29], biochemical hypothyroidism was found in 6/19 (31.6\%) patients. Hypercalcemia was more frequent (50\%) than the documented incidence in the WBS (15\%) [9]. This biochemical abnormality is mostly detected in the first year of life. The group of children less than one year in our series is small (4 children) so comparison may be not possible to establish a difference or a concordance with the literature.

\section{Conclusions}

The management of children with WBS requires an understanding of the natural course of the disorder, awareness of potential clinical complications, periodic review at different ages and specific treatment of developmen- 
tal, behavioral and medical problems of the syndrome, improving the prognosis, and allows an appropriate counseling for the family.

A policy statement released by the AAP in 2001—“Health care supervision for children with Williams syndrome"-[5] included a set of guidelines to assist the clinician to care for children with WBS from early infancy to adolescence and it is a good criteria to start WBS' patients investigation and to establish a calendar of review.

\section{Acknowledgements}

The authors thank all the patients and their family members for participating to this study. They thank all the stuff of hospitals participating to the study.

\section{Competing Interests}

The authors declare that they have no competing interests.

\section{Authors' Contributions}

IO, MC, IC, LK and RM carried out the molecular genetic studies, FM, MT, HA, FC, EBH, RB, AM and RM have made substantial contributions to or acquisition and interpretation of data, HBC have given final approval of the version to be published. All authors read and approved the final manuscript.

\section{References}

[1] Ewart, A.K., Morris, C.A., et al. (1993) Hemizygosity at the Elastin Locus in a Developmental Disorder, Williams Syndrome. Nature Genetics, 5, 11-16. http://dx.doi.org/10.1038/ng0993-11

[2] Curran, M.E., Atkinson, D.L., et al. (1993) The Elastin Gene Is Disrupted by a Translocation Associated with Supravalvular Aortic Stenosis. Cell, 73, 159-168. http://dx.doi.org/10.1016/0092-8674(93)90168-P

[3] Kenneth, K., Jones, L., et al. (1975) The Williams Elfin Facies Syndrome. A New Perspective. Journal of Pediatrics, 86, 718-723. http://dx.doi.org/10.1016/S0022-3476(75)80356-8

[4] Stamm, C., Friehs, I., et al. (2001) Congenital Supravalvar Aortic Stenosis: A Simple Lesion? European Journal Cardio-Thoracic Surgery, 19, 195-202. http://dx.doi.org/10.1016/S1010-7940(00)00647-3

[5] Beuren, A.J., Apitz, J., et al. (1962) Supravalvular Aortic Stenosis in Association with Mental Retardation and a Certain Facial Appearance. Circulation, 26, 1235-1240. http://dx.doi.org/10.1161/01.CIR.26.6.1235

[6] Williams, J.C., Barratt-Boyes, B.G., et al. (1961) Supravalvular Aortic Stenosis. Circulation, 24, 1311-1318. http://dx.doi.org/10.1161/01.CIR.24.6.1311

[7] Stromme, P., Bjornstrad, P.G., et al. (2002) Prevalence Estimation of Williams Syndrome. Journal of Child Neurology, 17, 269-271. http://dx.doi.org/10.1177/088307380201700406

[8] Beuren, A.J. (1972) Supravalvular Aortic Stenosis: A Complex Syndrome with and without Mental Retardation. Birth Defects Orig. Art. Series 8, 45-56.

[9] Committee on Genetics of American Academy of Pediatrics (2001) Health Care Supervision for Children with Williams Syndrome. Pediatrics, 107, 1192-1204.

[10] Lopez-Rangel, E., Maurice, M., et al. (1992) Williams Syndrome in Adults. American Journal of Medical Genetics, 44, 720-729. http://dx.doi.org/10.1002/ajmg.1320440605

[11] Morris, C.A., Demsey, S.A., Leonard, C.O., Dilts, C. and Blackburn, B.L. (1988) Natural History of Williams Syndrome: Physical Characteristics. The Journal of Pediatrics, 113, 328-325. http://dx.doi.org/10.1016/S0022-3476(88)80272-5

[12] Eronen, M., Peippo, M., Hiippala, A., Raatikka, M., Arvio, M., Johansson, R., et al. (2002) Cardiovascular Manifestations in 75 Patients with Williams Syndrome. Journal of Medical Genetics, 39, 554-558. http://dx.doi.org/10.1136/jmg.39.8.554

[13] Deruelle, C., Mancini, J., Livet, M.O., Cassé-Perrot, C. and de Schonen, S. (1993) Configural and Local Processing of Faces in Children with Williams Syndrome. Brain and Cognition, 41, 276-298. http://dx.doi.org/10.1006/brcg.1999.1127

[14] Mervis, C.B. and Klein-Tasman, B.P. (2000) Williams Syndrome: Cognition, Personality and Adaptative Behaviour. Mental Retardation and Developmental Disabilities Research Reviews, 6, 148-158. http://dx.doi.org/10.1002/1098-2779(2000)6:2<148::AID-MRDD10>3.0.CO;2-T 
[15] Udwin, O. and Yule, W. (1991) A Cognitive and Behavioural Phenotype in Williams Syndrome. Journal of Clinical and Experimental Neuropsychology, 13, 232-244. http://dx.doi.org/10.1080/01688639108401040

[16] Burn, J. (1986) Williams Syndrome. Journal of Medical Genetic, 23, 389-395. http://dx.doi.org/10.1136/jmg.23.5.389

[17] Osório, A., Cruz, R., Sampaio, A., Garayzábal, E., Martínez-Regueiro, R., Gonçalves, Ó.F., et al. (2012) How Executive Functions Are Related to Intelligence in Williams Syndrome. Research in Developmental Disabilities, 33, 11691175. http://dx.doi.org/10.1016/j.ridd.2012.02.003

[18] Levitin, D.J., Cole, K., Chiles, M., Lai, Z., Lincoln, A. and Bellugi, U. (2004) Characterizing the Musical Phenotype in Individuals with Williams Syndrome. Child Neuropsychology, 10, 223-247. http://dx.doi.org/10.1080/09297040490909288

[19] Frigerio, A., Burt, D.M., Gagliardi, C., Cioffi, G., Martelli, S., Perrett, D.I., et al. (2006) Is Everybody Always My Friend? Perception of Approachability in Williams Syndrome. Neuropsychologia, 44, 254-259. http://dx.doi.org/10.1016/j.neuropsychologia.2005.05.008

[20] Preus, M. (1984) The Williams Syndrome: Objective Definition and Diagnosis. Clinical Genetics, 25, $422-428$. http://dx.doi.org/10.1111/j.1399-0004.1984.tb02011.x

[21] Gimelli, S., Chrast, J., Baban, A., Henrichsen, C.N., Lerone, M., Zuffardi, O., et al. (2010) A t(7;12) Balanced Translocation with Breakpoints Overlapping Those of the Williams-Beuren and 12q14 Microdeletion Syndromes. American Journal of Medical Genetics Part A, 152A, 1285-1294. http://dx.doi.org/10.1002/ajmg.a.33365

[22] Von Dadelszen, P., Chitayat, D., Winsor, E.J.T., Cohen, H., MacDonald, C., Taylor, G., et al. (2000) De Novo 46,XX, $\mathrm{t}(6 ; 7)(\mathrm{q} 27 ; \mathrm{q11} ; 23)$ Associated with Severe Cardiovascular Manifestations Characteristic of Supravalvular Aortic Stenosis and Williams Syndrome. American Journal of Medical Genetics, 90, 270-275. http://dx.doi.org/10.1002/(SICI)1096-8628(20000214)90:4<270::AID-AJMG2>3.0.CO;2-R

[23] Donnai, D. and Karmiloff-Smith, A. (2000) Williams Syndrome: From Genotype through to the Cognitive Phenotype. American Journal of Medical Genetics, 97, 164-171. http://dx.doi.org/10.1002/1096-8628(200022)97:2<164::AID-AJMG8>3.0.CO;2-F

[24] Stinton, C., Elison, S. and Howlin, P. (2010) Mental Health Problems in Adults with Williams Syndrome. American Journal on Intellectual and Developmental Disabilities, 115, 3-18. http://dx.doi.org/10.1352/1944-7558-115.1.3

[25] Tordjman, S., Anderson, G.M., Botbol, M., Toutain, A., Sarda, P., Carlier, M., et al. (2012) Autistic Disorder in Patients with Williams-Beuren Syndrome: A Reconsideration of the Williams-Beuren Syndrome Phenotype. PLoS ONE, 7, e30778. http://dx.doi.org/10.1371/journal.pone.0030778

[26] Ferrero, G.B., Howald, C., Micale, L., Biamino, E., Augello, B., Fusco, C., et al. (2010) An Atypical 7q11.23 Deletion in a Normal IQ Williams-Beuren Syndrome Patient. European Journal of Human Genetics, 18, 33-38. http://dx.doi.org/10.1038/ejhg.2009.108

[27] Tassabehji, M. (2003) Williams-Beuren Syndrome: A Challenge for Genotype-Phenotype Correlations. Human Molecular Genetics, 12, R229-R237. http://dx.doi.org/10.1093/hmg/ddg299

[28] Cambiaso, P., Orazi, C., Digilio, M.C., Loche, S., Capolino, R., Tozzi, A., et al. (2007) Thyroid Morphology and Subclinical Hypothyroidism in Children and Adolescents with Williams Syndrome. The Journal of Pediatrics, 150, 62-65. http://dx.doi.org/10.1016/j.jpeds.2006.10.060

[29] Selicorni, A., Fratoni, A., Pavesi, M.A., Bottigelli, M., Arnaboldi, E. and Milani, D. (2006) Thyroid Anomalies in Williams Syndrome: Investigation of 95 Patients. American Journal of Medical Genetics Part A, 140A, 1098-1101. http://dx.doi.org/10.1002/ajmg.a.31210 
Scientific Research Publishing (SCIRP) is one of the largest Open Access journal publishers. It is currently publishing more than 200 open access, online, peer-reviewed journals covering a wide range of academic disciplines. SCIRP serves the worldwide academic communities and contributes to the progress and application of science with its publication.

Other selected journals from SCIRP are listed as below. Submit your manuscript to us via either submit@scirp.org or Online Submission Portal.
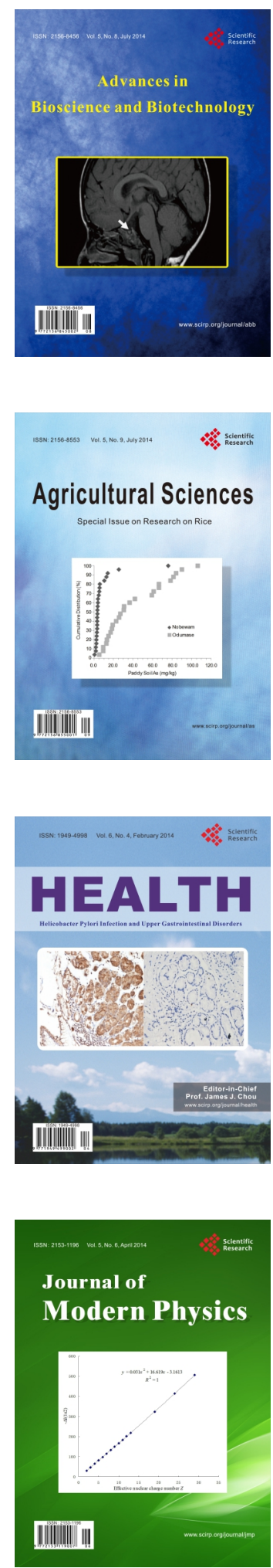
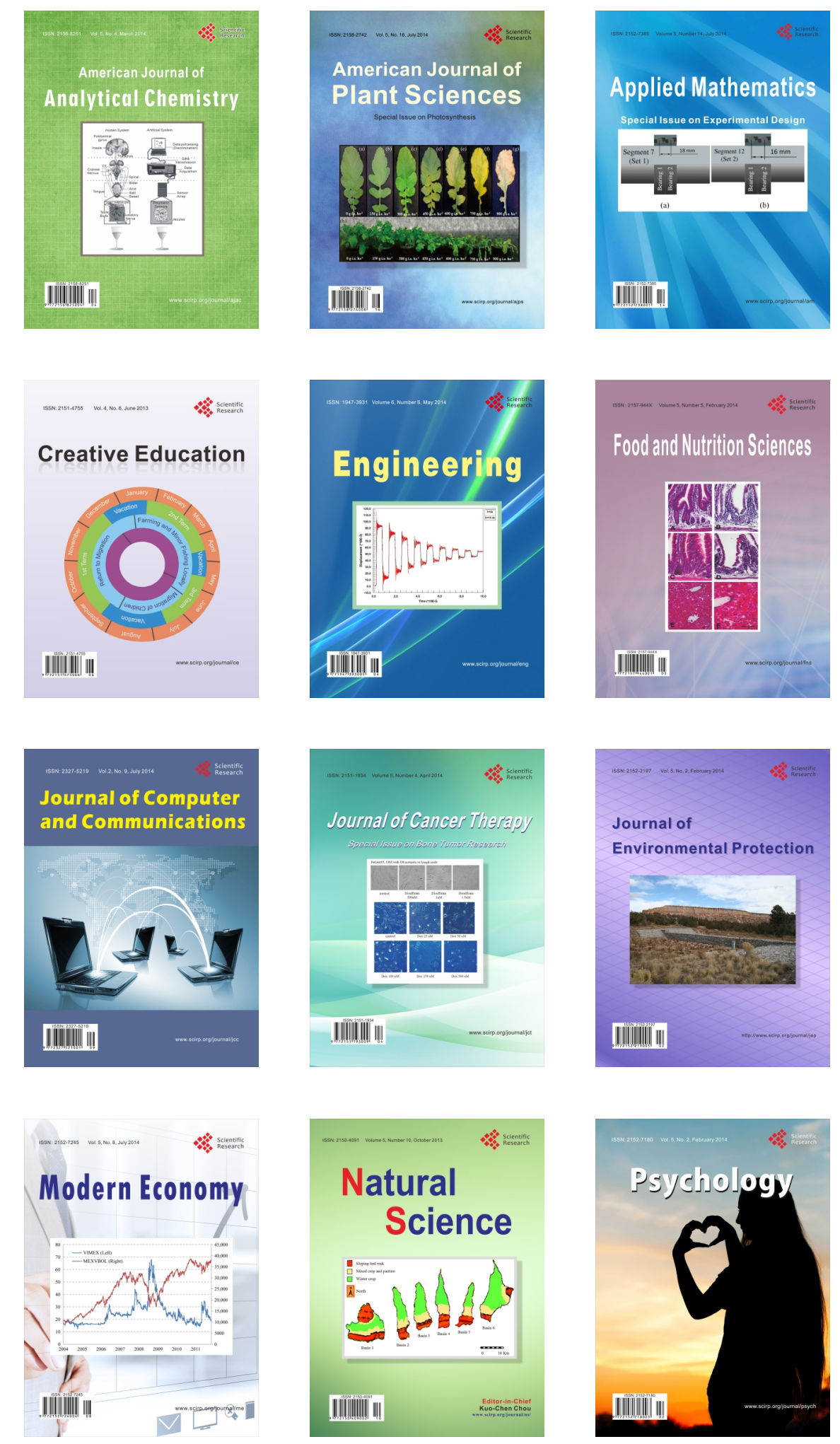